\title{
Laboratory evaluation of vasoreactivity; asymmetric dymethylarginine, nitric oxide, fibrinogen and high sensitive C-reactive protein in patients with polycystic ovary syndrome
}

\section{Süreyya Demir}

Dokuz Eylul Universitesi Tip Fakultesi

\section{Bulent Demir}

Canakkale Onsekiz Mart Universitesi Tip Fakultesi

Mehmet Nafi Sakar

Diyarbakir Gazi Yasargil Egitim ve Arastirma Hastanesi

semir pasa ( $\nabla$ semirp@hotmail.com )

Mardin Artuklu University https://orcid.org/0000-0001-8029-7622

\section{Yildiz Atamer}

Beykent Universitesi

\section{Research}

Keywords: Polycystic ovary syndrome, asymmetric dimethylarginine, high sensitivie C-reactive protein, vasoreactivity.

Posted Date: January 28th, 2020

DOI: https://doi.org/10.21203/rs.2.22028/v1

License: (c) (i) This work is licensed under a Creative Commons Attribution 4.0 International License.

Read Full License 


\section{Abstract}

Background-Aim We aimed to compare of fibrinogen, high sensitivie $\mathrm{C}$ reactive protein (hsCRP), asymmetric dymethylarginine (ADMA) and nitric oxide (NO) levels as laboratory parameters of vasoreactivity in patients with PCOS. Material and Methods Thirty patients with PCOS and 30 women with normal ovulating cycles were enrolled. Serum levels of NO, ADMA, fibrinogen, FSH, LH and hsCRP were assessed and compared with the control group. Results The mean ADMA, fibrinogen and hsCRP levels were significantly higher, and NO concentrations were lower in the patient group. A significant positive correlation was observed between ADMA and NO levels, ADMA and fibrinogen $(r=0.838, p<0.001)$, and ADMA and hsCRP concentrations. Fibrinogen and NO, and NO and hsCRP levels were significantly negatively correlated in the patient group. In the control group, there was a positive correlation between fibrinogen and age, and there was a negative correlation between $\mathrm{NO}$ and $\mathrm{FSH}$. Conclusion The present study determined positive relation between ADMA levels and vasoreactive parameters of patients with PCOS. Women with PCOS have elevated levels of ADMA, fibrinogen and decreased NO that make them candidates for cardiovascular disease. Further studies are required to establish the association of ADMA with vascular reactivity.

\section{Introduction}

Polycystic ovary syndrome (PCOS) is a common endocrine disorder affecting approximately $8-13 \%$ of women of reproductive age $(1,2)$. Although there are different criteria for defining the disorder, more important is the need to clearly define the phenotype of the patient being considered. PCOS phenotypes can generally be categorized into four types: a) phenotype $A$, demonstrating evidence of hyperandrogenemia (HA), either clinical, such as hirsutism, and/or biochemical, i.e., HA, ovulatory dysfunction (OD), often reflected by menstrual dysfunction, and (polycystic ovarian morphology) PCOM; b) phenotype $B$, which includes HA and OD, but not PCOM; $c$ ) phenotype $C$, including HA and PCOM, but not OD; and d) phenotype D, with OD and PCOM, but not HA. Metabolically, phenotypes A and B (also called "classic PCOS") behave similarly, with approximately $75 \%$ to $85 \%$ demonstrating insulin resistance (IR) and some form of metabolic dysfunction. These individuals have an increased risk of glucose intolerance and diabetes. PCOS women with phenotype D do not demonstrate overt evidence of androgen excess, have little evidence of metabolic dysfunction and are at low risk of developing disorders of glucose intolerance. Patients with phenotype C (often referred to as "ovulatory PCOS") have levels of metabolic dysfunction and risk that are somewhat less than those with the classic forms of PCOS but still measurably higher than those of control subjects or nonhyperandrogenic PCOS women $(3,4)$.

Asymmetric dymethylarginine (ADMA) is a novel regulator of nitric oxide (NO) production by inhibiting NO synthesis $(5,6)$. Recent observative studies revealed out that ADMA has significant effect on systemic vascular resistance (7). Plasma levels of ADMA apparently enhanced in atherosclerotic process and it was established that ADMA is an independant determinant of intima-media thickeness (IMT) (8). Elevated levels of ADMA stimulate vasoconstriction and platelet adhesion that facilitate the proatherogenic effect of the molecule $(6,9)$. 
Fibrinogen has been considered as an independent risk factor for cardiovascular disease (10). A number of studies have linked higher plasma fibrinogen concentrations with an increased risk of cardiovascular disease. (11). Women with PCOS have elevated levels of fibrinogen (12)

L-arginine derivate, NO, is a potent vasodilatator and protective against atherogenic states that acts by inhibiting thrombocyte aggregation, smooth muscle proliferation and inflammatory mediator production (13). Hyperinsulinemia and IR lead to decreased release of NO and increased production of fibrinogen that both reflect atherosclerosis (14). Women with PCOS reflect blunted response to NO-dependant vasodilatation which was demonstrated by many recent studies (13-17).

Inflammation and oxidative stress in PCOS condition is also manifested by the increase of high sensitive C reactive protein (hs-CRP), II-6 and chitotriosidase (ChT). Inflammatory state accompanies another element of PCOS in pathogenesis, which is the disorder in action and release activity of insulin. The growth of insulin level increases the production of androgens through the activity of ovarian theca cells (18).

Patients with PCOS exhibit increased vascular IMT and decreased flow mediated dilatation (1). Guzick et al. stated that women with PCOS have greater carotid IMT than healthy individuals. (19). Recent parameters of vascular reactivity like ADMA, NO and fibrinogen may provide complementary data on the evaluation of vascular complications of this disorder (8). PCOS is associated with low-grade systemic inflammation as evidenced by elevation of multiple markers of inflammation; such as II-6, ChT, hs-CRP and white blood cell count which also represent endothelial dysfunction and increased oxidative stress $(17-20)$.

In this presented study, we aimed to compare of fibrinogen, hs-CRP, ADMA and NO levels as laboratory parameters of vasoreactivity in patients with PCOS and healthy women, and to evaluate the possiable relation between these parametes and hormones of patients, to predict their possible cardiovascular effects.

\section{Patients And Methods}

Power analysis was performed using the mean values from the paper by Rashidi et al (21). The minimum sample size was calculated to be 29 patients in each group with $\% 90$ power and $5 \%$ alpha error. Age and $\mathrm{BMI}$ matched 30 patients with non-obese PCOS and 30 non-obese women with normal ovulating cycles were enrolled to this cross-sectional study with a comparison group. Diagnosis of PCOS was based on the revised Rotterdam criteria (PCOS Consensus Workshop 2004) (22). Patients with following criteria were included; amenorrhea or oligomenorrhea ( 6 cycles for each year), polycystic ovaries on ultrasonographic examination (presence of 12 or more follicles in each ovary measuring 2-9 $\mathrm{mm}$ in diameter, and/or increased ovarian volume $(>10 \mathrm{~mL})$ ) and clinical and/or biochemical evidences of HA. None of participants had been receiving any medication during the last 3 months. Patients with pregnancy, liver or renal dysfunction, smoking, obesity, diabetes mellitus, hypertension, hyperprolactinemia or thyroid disease were excluded. The study was approved by the ethical review 
committee of Dicle University, Diyarbakır, Turkey. Written informed constant was obtained from all participants.

All the participants were examined by the same physician, and ultrasonographic examination was performed by the same radiologist. BMI was determined as the ratio of weight in kilograms to height in meters $\left(\mathrm{kg} / \mathrm{m}^{2}\right)$.

Blood samples were obtained after 12-hour fasting period. Serum NO levels were measured by using a colorimetric method based on the Griess reaction, in which nitrite is reacted with sulphanilamide and $\mathrm{N}-(1-$ naphthyl) ethylenediamide to produce an azo dye that can be detected at $540 \mathrm{~nm}$. This was carried out after enzymatic reduction of nitrate to nitrite with nitrate reductase. ADMA was measured by high performance liquid chromatography (HPLC) according to the method described by Chen et al. (23). Fibrinogen concentration was measured in heparinized plasma and hs-CRP in serum by nephelometric method in BN ProSpec (Siemens) analyzer. Biochemical variables were analyzed by photometric method in Siemens Advia 1800 device.

Statistical Analysis: Statistical calculations were performed using the SPSS for Windows computer program (release 21.0; SPSS Inc., Chicago, IL, USA). Shapiro-Wilk test was used for determining whether variables are normally distributed. Normally distributed variables (age, BMI, FSH and fibrinogen) were analyzed with the student $t$ test. Non-normally distributed variables ( $\mathrm{LH}, \mathrm{LH} / \mathrm{FSH}$ ratio, ADMA, NO, hsCRP) were analyzed with the Mann Whitney $U$ test. Data are expressed as mean \pm standard deviation or median (minimum - maximum) according normality. Pearson or Spearman correlation coefficients (depending normality) were calculated to evaluate relationships between the various parameters studied. A P-value $<0.05$ was considered to be statistically significant.

\section{Results}

The mean age of patients and control subjects were similar $(p=0.560)$. Patients with PCOS had slightly higher BMI when compared to control subjects, however this difference did not achieve statistical significance $(p=0.505)$, and there was no significant difference between groups in terms of FSH levels $(p=0.908)$ as shown in table 1. LH levels of the patients were significantly higher than the control subjects $(\mathrm{p}<0.005)$.

The mean ADMA levels were significantly higher in the patient group than in control group (1.22 vs 0.52 , respectively). Plasma concentrations of fibrinogen and hsCRP were significantly higher in patients with PCOS than control group ( $p<0.001$ for both). As expected, NO concentrations were significantly lower in patient group than patient group $(\mathrm{p}<0.001)$.

A significant positive correlation was observed between ADMA and NO levels in the patient group $(r=0.916, p<0.001)$. Also, there was a significant correlation between ADMA and fibrinogen $(r=0.838$, $p<0.001)$ and, between ADMA and hsCRP concentrations $(r=0.889, p<0.001)$. Fibrinogen and NO, and NO and hsCRP levels were significantly correlated in the patient group $(r=0.783$ and $r=0.799$; respectively and 
$p<0.001$ for both) (Table 2) (Figure 1 to 6 ). In the control group, there was a positive correlation between fibrinogen and age $(r=0.404, p=0.027)$ and there was a negative correlation between $\mathrm{NO}$ and FSH $(r=-0.411, p=0.024)($ Table 3$)$.

\section{Discussion}

PCOS is a complex endocrine disorder which has hormonal and metabolic components. Although hormonal disturbances of PCOS is relatively well-established, discrepancy still exist in the pathogenesis of metabolic component. We determined a positive correlation between ADMA and fibrinogen or hsCRP, and inverse correlation between ADMA and NO in PCOS patients. To the best of our knowledge, this is the first report that examined the relation of ADMA, fibrinogen and nitric oxide with metabolic and hormonal parameters of nonobese PCOS patients by comparing nonobese healthy controls.

Endothelial dysfunction is regarded as the initial step in the development of atherosclerotic process (24). Hyper insulinemia, hyperlipidemia, HA and obesity; which are frequently observed in patients with PCOS, are well-known risk factors of vascular complications of the syndrome and exert synergistic effect (25). Duration of exposure to HA and hyper insulinemic environment have significant impact on metabolic and hormonal parameters. Some recent reports mentioned that cardiovascular risk factors are evident in women with PCOS even at the $2^{\text {nd }}$ or $3^{\text {rd }}$ decade of life $(26,27)$. Cibula et al. reported that PCOS women are under higher risk of cardiovascular events than control subjects before age of 45 years. However little difference was observed in risk factors after 45 years (28). Conversely Talbott et al. determined that women with PCOS younger than 45 years and age matched healthy individuals have similar metabolic parameters and carotid intima-media thickness (29). There was a serious heterogeneity in age distribution and wide range in BMI in patient group in a previous report (30). Obesity have additional deleterious effects on glucose tolerance and endothelial functions in patients with PCOS (31). Our study group consisted of relatively young ( $<26$ years) nonsmoker and non-obese individuals, and we obtained age and BMI matched control group to eliminate the negative effect of age, smoking and obesity on hormonal and metabolic parameters. Elevated LH concentrations suggest the presence of HA which is a result of increased synthesis and/or decreased excretion of androgens or androgen precursors (32). Although HA is regarded as a contributor of endothelial dysfunction, there are controversial results with respect to effects of androgens on vascular functions $(33,34)$. Our results were in line with previous reports that mentioned to higher levels of $\mathrm{LH}$ and increased LH/FSH ratio in patients with PCOS when compared to healthy controls (10). Additionally, the relation of LH and FSH with ADMA level was nonsignificant.

A growing number of evidences have linked elevated fibrinogen levels with increased risk of cardiovascular disease (11). Some recent reports indicated that increased fibrinogen level is a marker of endothelial dysfunction $(18,35)$. Several experimental and epidemiologic studies; both in human and animal models, demonstrated an association between fibrinogen and atherosclerosis-related disorders including hypertension, diabetes mellitus, myocardial infarction and stroke (36). As expected, we 
observed significantly higher levels of fibrinogen in patients with PCOS and significant correlation of fibrinogen with ADMA and NO levels.

Heutling et al. found significantly elevated levels of hsCRP which was associated with increased risk of CVD (31). Kopp et al. demonstrated a decrease in inflammatory markers subsequent to weight loss (37). Preliminary data suggest that; in the absence of obesity and smoking, elevated hsCRP is likely to be associated with low grade inflammation resulted with endothelial dysfunction and atherosclerosis in patients with PCOS (38).

Currently available data from experimental studies document that NO regulate blood flow and has multiple endocrinologic and metabolic functions on human physiology such as ovulation, pubertal maturation, embryogenesis and timing of menopause as well as potentiating tissue responsiveness to insulin $(24,25,39)$. Decreased NO production by endothelial cells contributes to elevated blood pressure and systemic vascular resistance (40). In our study, patients have significantly lower NO levels than control subjects; consistent with recent reports.

ADMA is a competitive antagonist of NO synthesis and proposed to implicate in disorders related with NO dysfunction including DM, chronic kidney disease, congestive heart failure and atherosclerosis (41). ADMA is considered as an independent marker of cardiovascular morbidity and mortality (33). Charitidou et al. stated that ADMA has an advantage of predicting atherosclerotic process and development of cardiovascular events which was not attributed to traditional risk factors (7). However, Pamuk et al. and Demirel et al. determined similar levels of ADMA in patients with PCOS and control subjects $(30,42)$. Current clinical and experimental data showed that slight increase in ADMA concentrations; particularly those with PCOS, resulted with higher risk of cardiovascular events that make candidates for ischemic vascular diseases (43).

We failed to demonstrate a correlation between NO and LH levels. Mather et al. determined that HA or hypergonadotrophinemia have no direct influence on NO concentrations (44). We observe a close relation between hsCRP and ADMA and, fibrinogen and ADMA. Our results were in agreement with those reported by Heutling et al. and Krzyzanowska et al. $(33,45)$. Also, NO levels were significantly but inversely correlated with ADMA, fibrinogen and hsCRP.

The present study has some limitations. The major limitation was low sample size due to strict exclusion criteria that obese, smoker, old patients or received any medication in last 3 months were not enrolled. Second, more than single point measurement may enhance significance of the results. Third, long term follow-up needed to demonstrate possible cardiac effects of these inflammatory changes. Finally, the effect of medical therapy on these parameters may help better understanding.

\section{Conclusion}

We determined higher circulating ADMA and fibrinogen and, lower NO levels which are associated with worse metabolic profile that may reflect endothelial dysfunction in PCOS patients. Although cardiac 
effects are expected, further studies are required to clarify this data.

\section{List Of Abbreviations}

ADMA: Asymmetric dymethylarginine

ChT: Chitotriosidase

HA: Hyperandrogenemia

HPLC: high performance liquid chromatography

hsCRP: High sensitivie $\mathrm{C}$ reactive protein (hsCRP)

IMT: Intima-media thickeness

IR: Insulin resistance

NO: Nitric oxide

OD: Ovulatory dysfunction

PCOM: Polycystic ovarian morphology

PCOS: Polycystic ovary syndrome

\section{Declarations}

Ethics Committee Approval: The research protocol of this study was approved by Dicle University Ethical Comission (under code of: 95/10.07.12).

Consent for Publication: Not Applicaple.

Availability of data and materials: All data generated or analysed during this study are included in this published article.

Competing Interests: The athors declared that there is no conflict of interests.

Funding: The Authors declared this study received no financial support.

\section{Author's Contributions:}

Sureyya Demir, Bulent Demir and Mehmet Nafi Sakar are gyneacologists: Examine the patients and collect data. Sureyya Demir designed the study.

Semir Pasa: Intenist and Endocrinologist. Evaluate the vosoreactivity in these patients. 
Yildiz Atamer: Biochemistrician. Contribute on Laboratory studies.

Acknowledgements: Not applicable.

\section{References}

1) Franks S. Polycystic ovary syndrome. N Engl J Med 1995; 333: 853-61.

2) Escobar-Morreale HF. Polycystic ovary syndrome: definition, aetiology, diagnosis and treatment. Nat Rev Endocrinol 2018; 14(5): 270-84.

3) Murphy MK, Hall JE, Adams JM, Lee H, Welt CK. Polycystic ovarian morphology in normal women does not predict the development of polycystic ovary syndrome. J Clin Endocrinol Metab. 2006; 91: 3878-84.

4) Lizneva D, Suturina L, Walker W, Brakta S, Gavrilova-Jordan L, Azziz R. Criteria, prevalence, and phenotypes of polycystic ovary syndrome. Fertil Steril. 2016;106(1):6-15.

5) Vallance P, Leone A, Calver A, Collier J, Moncada S. Accumulation of an endogenous inhibitor of NO synthesis in chronic renal failure. Lancet 1992; 339: 572-5.

6) Sohaei S, Amani R, Tarrahi MJ, Ghasemi-Tehrani H. The effects of curcumin supplementation on glycemic status, lipid profile and hs-CRP levels in overweight/obese women with polycystic ovarysyndrome: A randomized, double-blind, placebo-controlled clinical trial. Complement Ther Med. 2019 Dec;47:102201. doi: 10.1016/j.ctim.2019.102201

7) Charitidou C, Farmakiotis D, Zournatzi V, Pidonia I, Pegiou T, Karamanis N, Hatzistilianou M, Katsikis I, Panidis $D$. The administration of estrogens, combined with anti-androgens, has beneficial effects on the hormonal features and asymmetric dimethyl-arginine levels, in women with the polycystic ovary syndrome. Atherosclerosis. 2008; 196: 958-65.

8) Boger RH, Maas R, Schulze F, Schwedhelm E. Elevated levels of asymmetric dimethylarginine (ADMA) as a marker of cardiovascular disease and mortality. Clin Chem Lab Med 2005; 43: 1124-9.

9) Miyazaki H, Matsuoka H, Cooke JP, Usui M, Ueda S, Okuda S, Imaizumi T, Cooke JP. Endogenous nitric oxide synthase inhibitor: a novel marker of atherosclerosis. Circulation 1999; 99: 1141-6.

10) Nacul A.P, Andrade C.D, Schwarz P., Homem de Bittencourt P.I., Spritzer P.M. Nitric oxide and fibrinogen in polycystic ovary syndrome: Associations with insülin resistance and obesity. Eur J Obs Gynecol Rep Biol. 2007; 133: 191-6.

11) Folsom AR, Pankow JS, Williams RR, Evans GW, Province MA, Eckfeldt JH. Fibrinogen, plasminogen activator inhibitor-1, and carotid intima-media wall thickness in the NHLBI Family Heart Study. Thromb Haemost. 1998; 79: 400-4. 
12) Yildiz BO, Haznedaroglu IC, Kirazli S, Bayraktar M. Global fibrinolytic capacity decreased in polycystic ovary syndrome, suggesting a prothrombotic state. J Clin Endocrinol Metab 2002; 87: 3871-5.

13) Ozgurtas T, Oktenli Cl, Dede M, Tapan S, Kenar L, Sanisoglu SY, Yesilova Z, Yenen MC, Erbil MK, Baser I. Metformin and oral contraceptive treatments reduced circulating asymmetric dimethylarginine (ADMA) levels in patients with polycystic ovary syndrome (PCOS). Atherosclerosis. 2008; 200: 336-44.

14) Lindahl $B$, Asplund K, Eliasson M, Evrin P. Insulin resistance syndrome and fibrinolytic activity: The Northern Sweden MONICA study. Int J Epidemiol 1996; 25: 291-9.

15) Lakhani K, Leonard A, Seifalian AM, Hardiman P. Microvascular dysfunctioin women with polycystic ovary syndrome. Hum Reprod 2005; 20: 3219-24.

16) Meng C. Nitric oxide (NO) levels in patients with polycystic ovary syndrome (PCOS): A meta-analysis. J Int Med Res 2019; 47(9): 4083-94.

17) Krishnaa MB, Josepha A, Thomasa PL, Dsilva B, Pillai SM, Laloraya M. Impaired Arginine Metabolism Coupled to a Defective Redox Conduit Contributes to Low Plasma Nitric Oxide in Polycystic Ovary Syndrome. Cell Physiol Biochem 2017; 43: 1880-92.

18) Szczuko M, Zapałowska-Chwyc M, Drozd A, Maciejewska D, Starczewski A, Stachowska E. Effect of IGF-I and TNF-a on intensification of steroid pathways in women with PCOS phenotypes are not identical. Enhancement of progesterone pathway in women with PCOS increases the concentration of TNF-a. Gynecol Endocrinol 2016; 32(9): 714-7.

19) Guzick DS, Talbott EO, Sutton-Tyrrell K, Herzog HC, Kuller LH, Wolfson SK Jr. Carotid atherosclerosis in women with polycystic ovary syndrome: Initial results from a case-control study. Am J Obstet Gynecol. 1996; 174: 1224-9.

20) Talbott E.O, Zborowski J.V., Sutton-Tyrrell K., McHugh-Pemu K.P., Guzick D.S. Cardiovascular Risk in Women with Polycystic Ovary Syndrome. Obs Gynecol Clin North America. 2001; 28: 111-29.

21) Rashidi BH, Gorginzadeh M, Aalipour S, Sills ES. Age related endocrine patterns observed in polycystic ovary syndrome patients vs. ovulatory controls: descriptive data from a university based infertility center. Arch Endocrinol Metab. 2016; 60(5): 486-491.

22) Rotterdam ESHRE/ASRM-Sponsored PCOS Consensus Workshop Group. Revised 2003 consensus on diagnostic criteria and long-term health risks related to polycystic ovary syndrome. Fertil Steril. 2004; 81(1): 19-25.

23) Chen GF, Wagner L, Sasser JM, Zharikov S, Moningka NC, Baylis C. Effects of angiotensin type 1 receptor blockade on arginine and ADMA synthesis and metabolic pathways in fawn-hooded hypertensive rats. Nephrol Dial Transplant. 2010; 25: 3518-25. 
24) Walch K, Kolbus A, Hefler-Frischmuth K. Polymorphisms of the endothelial nitric oxide synthase gene in premenopausal women with polycystic ovary syndrome. Maturitas. 2008; 61: 256-9.

25) Ngo DTM, Chan WP, Rajendran S, Heresztyn T, Amarasekera A, Sverdlov AL, O'Loughlin PD, Morris HA, Chirkov YY, Norman RJ, Horowitz JD. Determinants of insulin responsiveness in young women: Impact of polycystic ovarian syndrome, nitric oxide, and vitamin D. Nitric Oxide. 2011; 25: 326-30.

26) Talbott EO, Guzick DS, Sutton-Tyrrell K, McHugh-Pemu KP, Zborowski JV, Remsberg KE, Kuller LH. Evidence for association between polycystic ovary syndrome and premature carotid atherosclerosis in middle-aged women. Arterioscler Thromb Vasc Biol 2000; 20: 2414-21.

27) Lakhani K, Hardiman P, Seifalian AM. Intima-media thickness of elastic and muscular arteries of young women with polycystic ovaries. Atherosclerosis 2004; 175: 353-9.

28) Cibula $D$, Cifkova $R$, Fanta $M$, et a1 Increased risk of non-insulin dependent diabetes mellitus, arterial hypertension and coronary artery disease in perimenopausal women with a history of the polycystic ovary syndrome. Hum Reprod 2000; 15: 785-9.

29) Talbott EO, Zborowski JV, Rager JR, BoudreauxMY, EdmundowiczDA, Guzick DS. Evidence for an association between metabolic cardiovascular syndrome and coronary and aortic calcification among women with polycystic ovary syndrome. J Clin Endocrinol Metab 2004; 89: 5454-61.

30) Pamuk B.O, Torun A.N, Kulaksizoglu M, Ertugrul D, Ciftci O, Kulaksizoglu S, Yildirim E, Demirag N.G. Asymmetric dimethyl-arginine levels and carotid intima-media thickness in obese patients with polycystic ovary syndrome and their relationship to metabolic parameters. Fertility and Sterility. 2010; 93: 1227-33.

31) Dunaif A, Segal KR, Futterweit W, Dobrjansky A. Profound peripheral insulin resistance, independent of obesity, in polycystic ovary syndrome. Diabetes 1989; 38: 1165-74.

32) Mai K, Bobbert T, Reinecke F, Andres J, Maser-Gluth C, Wudy SA, Mohlig M, Weickert MO, Hartmann MF, Schulte HM, Diederich S, Pfeiffer AFH, Spranger J. Intravenous Lipid and Heparin Infusion-Induced Elevation in Free Fatty Acids and Triglycerides Modifies Circulating Androgen Levels in Women: A Randomized, Controlled Trial. J Clin Endocrinol Metab. October 2008, 93: 3900-6.

33) Heutling D, Schulz H, Nickel I, Kleinstein J, Kaltwasser P, Westphal S, Mittermayer F, Wolzt M, Krzyzanowska K, Randeva H, Schernthaner G, Lehnert H. Asymmetrical Dimethylarginine, Inflammatory and Metabolic Parameters in Women with Polycystic Ovary Syndrome before and after Metformin Treatment. J Clin Endocrinol Metab. January 2008, 93(1): 82-90.

34) Dagre A, Lekakis J, Mihas C, Protogerou A, Thalassinou L, Tryfonopoulos D, Douridas G, Papamichael C, Alevizaki M. Association of dehydroepiandrosterone- sulfate with endothelial function in young women with polycystic ovary syndrome. Eur J Endocrinol 2006; 154: 883-90. 
35) Dereli D, Ozgen G, Buyukkececi F, Guney E, Yilmaz C. Platelet dysfunction in lean women with polycystic ovary syndrome and association with insulin sensitivity. J Clin Endocrinol Metab 2003; 88: 2263-8.

36) Ernst E, Resch KL. Fibrinogen as a cardiovascular risk factor: a meta-analysis and review of the literature. Ann Intern Med 1993; 118: 956-63.

37) Kopp HP, Kopp CW, Festa A, Krzyzanowska K, Kriwanek S, Minar E, Roka R, Schernthaner G. Impact of weight loss on inflammatory proteins and their association with the insulin resistance syndrome in morbidly obese patients. Arterioscler Thromb Vasc Biol 2003; 23: 1042-7.

38) Mohlig M, Spranger J, Osterhoff M, Ristow M, Pfeiffer AF, Schill T, Schlosser HW, Brabant G, Schofl C. The polycystic ovary syndrome per se is not associated with increased chronic inflammation. Eur $\mathrm{J}$ Endocrinol 2004; 150: 525-32.

39) Tempfer C, Unfried G, Zeillinger R, Hefler L, Nagele F, Huber J. Endothelial nitric oxide synthase gene polymorphism in women with idiopathic recurrent miscarriage. Hum Reprod 2001; 16: 1644-7.

40) Demir B, Pasa S, Demir S, Buyukkaya R, Atay AE, Atamer Y, Gul T. Morphologic and functional vascular alterations in patients with polycystic ovary syndrome. Clin Exp Obstet Gynecol 2011; 38(4): 401-4.

41) Lowe DT. Nitric oxide dysfunction in the pathophysiology of preeclampsia. Nitric Oxide. 2000; 4(4): 441-58.

42) Demirel F, Bideci A, Cinaz P, Camurdan MO, Biberoglu G, Yesilkaya E, Hasanoglu A. Serum leptin, oxidized low density lipoprotein and plasma asymmetric dimethylarginine levels and their relationship with dyslipidaemia in adolescent girls with polycystic ovary syndrome. Clin Endocrinol (Oxf) 2007; 67: 129-34.

43) Valkonen VP, Paiva H, Salonen JT, Lakka TA, Lehtimaki T, Laakso J, Laaksonen R. Risk of acute coronary events and serum concentration of asymmetrical dimethylarginine. Lancet 2001; 358: 2127-8.

44) Mather KJ, Verma S, Coreblum B, Anderson TJ. Normal endothelial function despite insulin resistance in health women with the polycystic ovary syndrome. J Clin Endocrinol Metab 2000; 85: 1851-6.

45) Krzyzanowska K, Mittermayer F, Kopp HP, Wolzt M, Schernthaner G. Weight loss reduces circulating asymmetrical dimethylarginine concentrations in morbidly obese women. J Clin Endocrinol Metab 2004; 89: 6277-81.

\section{Tables}


Table 1. Demographic features, metabolic and hormonal parameters of patients and control subjects

\begin{tabular}{lcccc}
\hline & \multicolumn{2}{c}{ Groups } & Total & $\mathrm{p}$ \\
\cline { 2 - 3 } & Patients $(\mathrm{n}=30)$ & Controls $(\mathrm{n}=30)$ & $26.05 \pm 4.60$ & 0.560 \\
\hline Age & $26.40 \pm 4.46$ & $25.70 \pm 4.78$ & $25.93 \pm 3.12$ & 0.505 \\
\hline BMI & $26.20 \pm 3.21$ & $25.66 \pm 3.05$ & $5.96 \pm 1.59$ & 0.908 \\
\hline FSH & $5.93 \pm 1.58$ & $5.61(1.60-12.30)$ & $5.35(1.60-32.63)$ & 0.005 \\
LH & $6.80(2.21-32.63)$ & $0.73(0.27-2.35)$ & $0.89(0.27-4.73)$ & 0.008 \\
\hline LH/FSH Ratio & $1.27(0.39-4.73)$ & $0.52(0.34-0.82)$ & $0.72(0.34-1.86)$ & $<0.001$ \\
ADMA & $1.22(0.65-1.86)$ & $2.63 \pm 0.71$ & $4.03 \pm 1.59$ & $<0.001$ \\
NO & $53.55(33.10-63.40)$ & $72.20(56.60-95.20)$ & $59.90(33.10-95.20)$ & $<0.001$ \\
\hline Fibrinogen & $5.43 \pm 0.77$ & $1.85(1.10-6.40)$ & $6.25(1.10-16.20)$ & $<0.001$ \\
\hline $\begin{array}{l}\text { HsCRP } \\
\text { Data are given } \\
\text { normality }\end{array}$ & $13.35(6.20-16.20)$ & & &
\end{tabular}

Table 2. Relationship between variables for the patients group

\begin{tabular}{|c|c|c|c|c|c|c|c|c|c|}
\hline & & BMI & FSH & LH & LH/FSH Ratio & ADMA & $\mathrm{NO}$ & Fibrinogen & HsCRP \\
\hline \multirow[t]{2}{*}{$\overline{\text { Age }}$} & $\mathrm{r}$ & 0,255 & 0,099 & 0.194 & 0.160 & -0.157 & -0.121 & $-0,164$ & -0.251 \\
\hline & $\mathrm{p}$ & 0,174 & 0,603 & 0.304 & 0.397 & 0.406 & 0.523 & 0,385 & 0.182 \\
\hline \multirow[t]{2}{*}{$\overline{\mathrm{BMI}}$} & $\mathrm{r}$ & & $-0,093$ & -0.210 & -0.230 & 0.045 & -0.045 & $-0,088$ & 0.017 \\
\hline & $\mathrm{p}$ & & 0,627 & 0.265 & 0.221 & 0.813 & 0.814 & 0,643 & 0.930 \\
\hline \multirow[t]{2}{*}{ FSH } & $\mathrm{r}$ & & & 0.325 & -0.101 & -0.086 & -0.022 & 0,058 & -0.045 \\
\hline & $\mathrm{p}$ & & & 0.080 & 0.595 & 0.652 & 0.907 & 0,763 & 0.815 \\
\hline \multirow[t]{2}{*}{$\mathrm{LH}$} & $r$ & & & & 0.886 & 0.090 & -0.023 & 0.214 & -0.081 \\
\hline & $\mathrm{p}$ & & & & $<0.001$ & 0.638 & 0.902 & 0.256 & 0.67 \\
\hline \multirow[t]{2}{*}{ LH/FSH Ratio } & $\mathrm{r}$ & & & & & 0.055 & -0.065 & 0.153 & -0.129 \\
\hline & $\mathrm{p}$ & & & & & 0.771 & 0.734 & 0.420 & 0.496 \\
\hline \multirow[t]{2}{*}{$\overline{\mathrm{ADMA}}$} & $\mathrm{r}$ & & & & & & 0.916 & 0.838 & 0.889 \\
\hline & $\mathrm{p}$ & & & & & & $<0.001$ & $<0.001$ & $<0.001$ \\
\hline \multirow[t]{2}{*}{ NO } & $\mathrm{r}$ & & & & & & & 0.783 & 0.799 \\
\hline & $\mathrm{p}$ & & & & & & & $<0.001$ & $<0.001$ \\
\hline \multirow[t]{2}{*}{ Fibrinogen } & $\frac{r}{r}$ & & & & & & & & 0.800 \\
\hline & $\mathrm{p}$ & & & & & & & & $<0.001$ \\
\hline
\end{tabular}

r: Correlation Coefficient 
Table 3. Relationship between variables for the controls group

\begin{tabular}{|c|c|c|c|c|c|c|c|c|c|}
\hline & & BMI & FSH & LH & LH/FSH Ratio & ADMA & $\mathrm{NO}$ & Fibrinogen & HsCRP \\
\hline \multirow[t]{2}{*}{ Age } & $\mathrm{r}$ & 0.125 & 0.053 & -0.039 & -0.060 & -0.062 & -0.279 & 0.404 & 0.231 \\
\hline & $\mathrm{p}$ & 0.509 & 0.781 & 0.840 & 0.753 & 0.744 & 0.135 & 0.027 & 0.220 \\
\hline \multirow[t]{2}{*}{ BMI } & $\mathrm{r}$ & & -0.029 & 0.023 & 0.012 & -0.167 & 0.119 & 0.101 & 0.195 \\
\hline & $\mathrm{p}$ & & 0.877 & 0.903 & 0.950 & 0.379 & 0.530 & 0.595 & 0.303 \\
\hline \multirow[t]{2}{*}{ FSH } & $\mathrm{r}$ & & & -0.027 & -0.474 & 0.051 & -0.411 & 0.076 & 0.292 \\
\hline & $\mathrm{p}$ & & & 0.889 & 0.008 & 0.790 & 0.024 & 0.688 & 0.117 \\
\hline \multirow[t]{2}{*}{$\overline{\mathrm{LH}}$} & $\mathrm{r}$ & & & & 0.838 & 0.039 & 0.041 & 0.278 & 0.178 \\
\hline & $\mathrm{p}$ & & & & $<0.001$ & 0.837 & 0.828 & 0.137 & 0.347 \\
\hline \multirow[t]{2}{*}{ LH/FSH Ratio } & $\mathrm{r}$ & & & & & -0.012 & 0.186 & 0.181 & -0.009 \\
\hline & $\mathrm{p}$ & & & & & 0.950 & 0.326 & 0.340 & 0.961 \\
\hline \multirow[t]{2}{*}{$\overline{\mathrm{ADMA}}$} & $\mathrm{r}$ & & & & & & -0.323 & 0.073 & -0.041 \\
\hline & $\mathrm{p}$ & & & & & & 0.081 & 0.700 & 0.831 \\
\hline \multirow[t]{2}{*}{$\mathrm{NO}$} & $r$ & & & & & & & -0.141 & -0.304 \\
\hline & $\mathrm{p}$ & & & & & & & 0.459 & 0.102 \\
\hline \multirow[t]{2}{*}{ Fibrinogen } & $\mathrm{r}$ & & & & & & & & 0.148 \\
\hline & $\mathrm{p}$ & & & & & & & & 0.436 \\
\hline
\end{tabular}

r: Correlation Coefficient

Figures

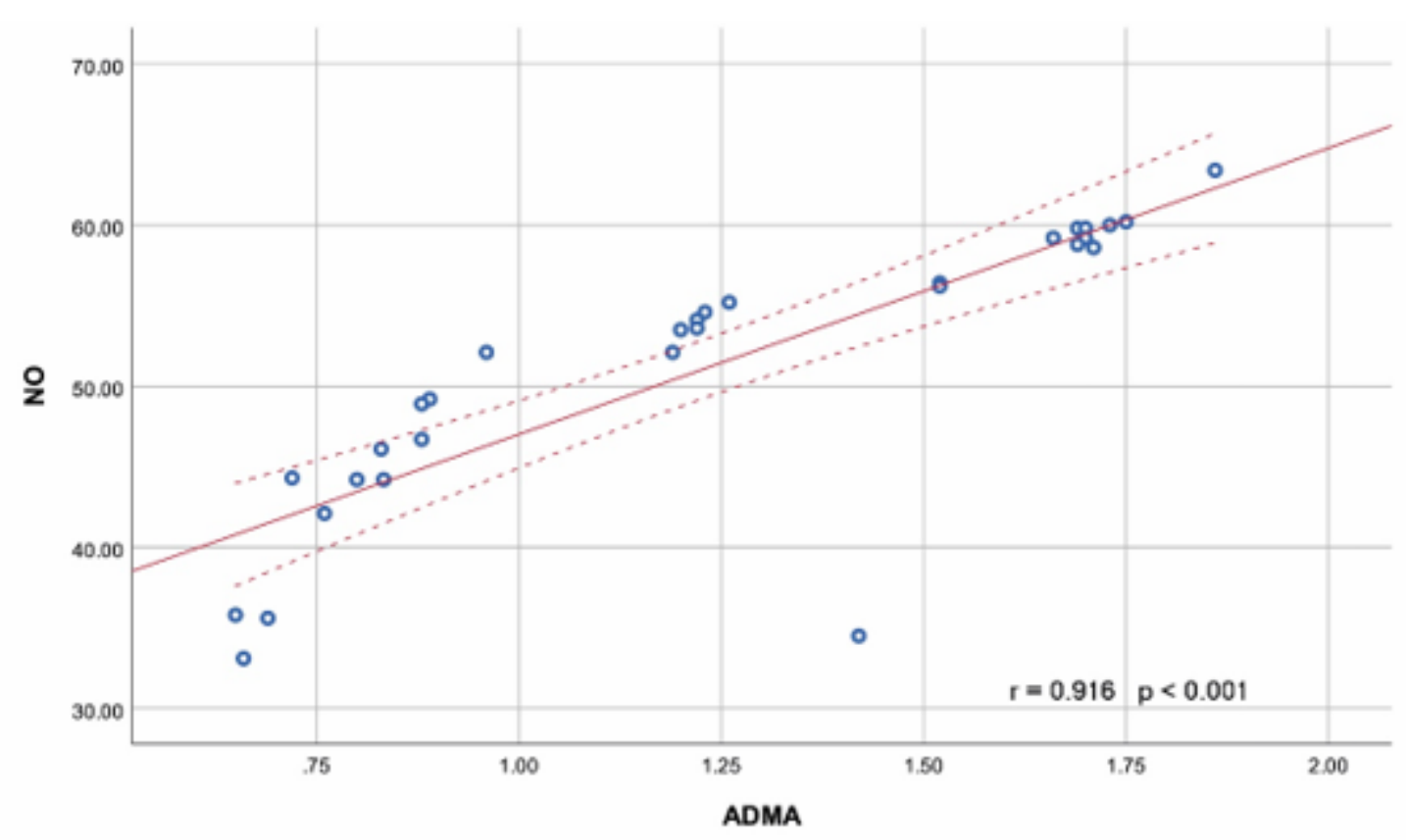

Figure 1 
Relationship between NO and ADMA for the patients group

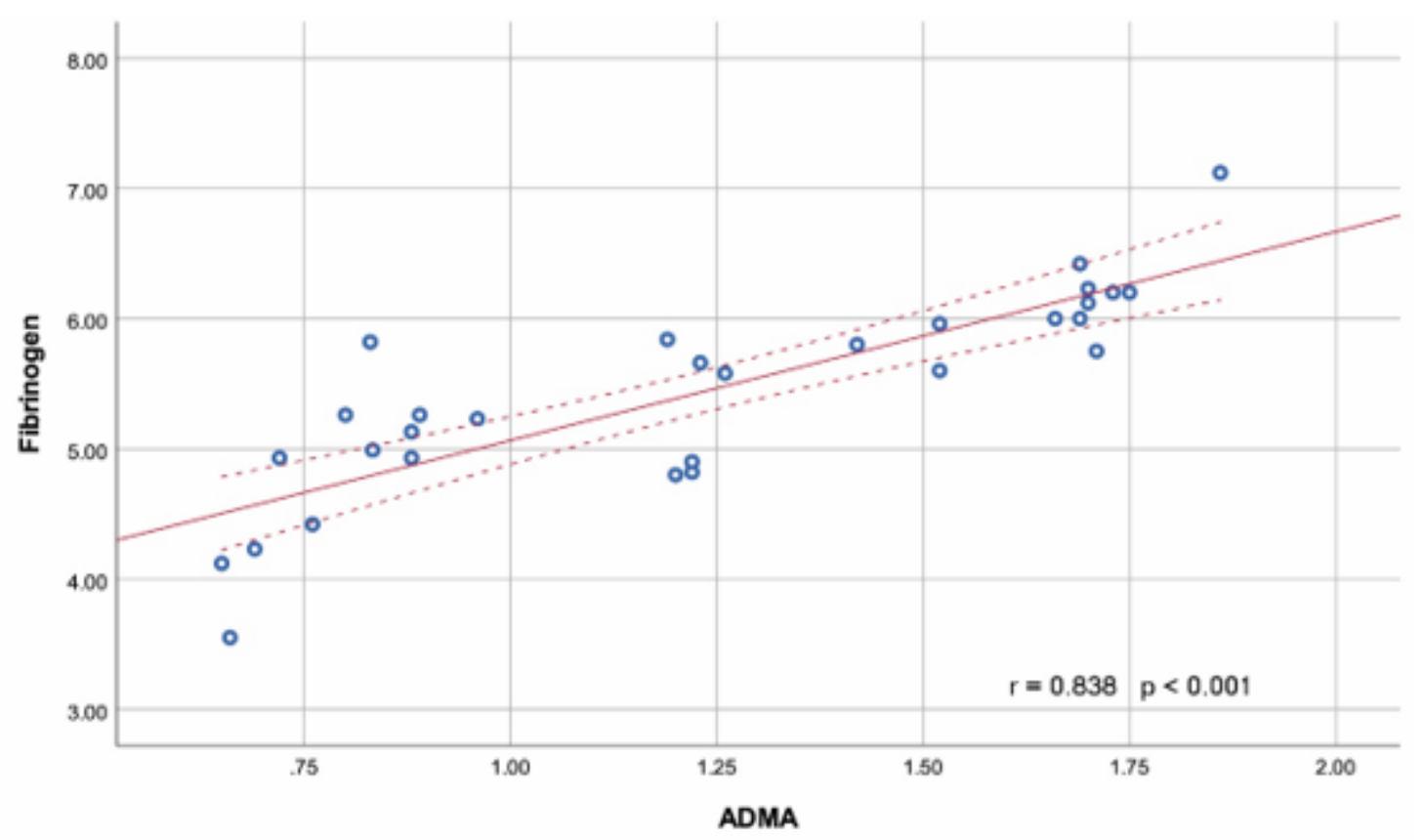

Figure 2

Relationship between fibrinogen and ADMA for the patients group

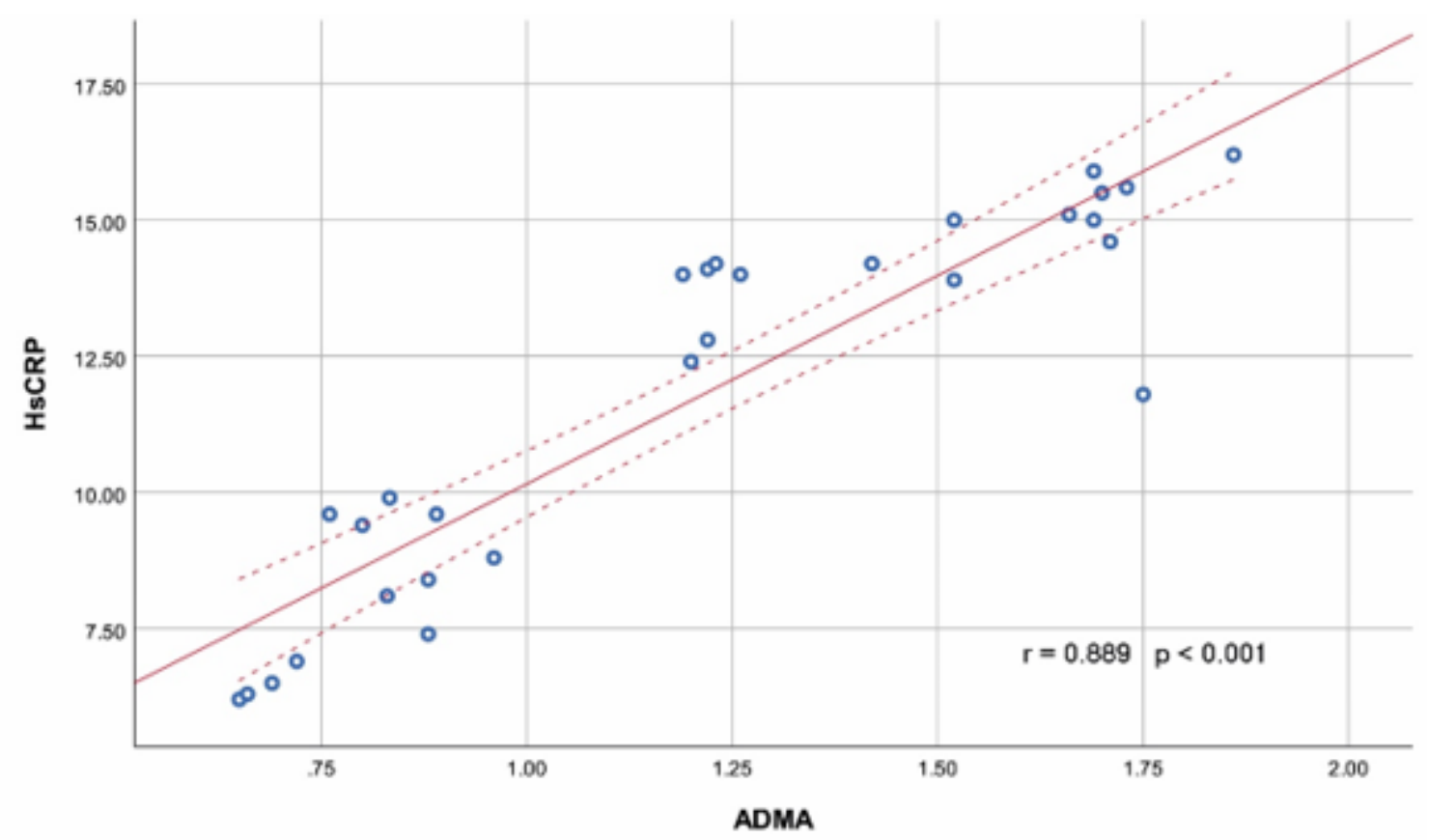

Figure 3

Relationship between HsCRP and ADMA for the patients group 


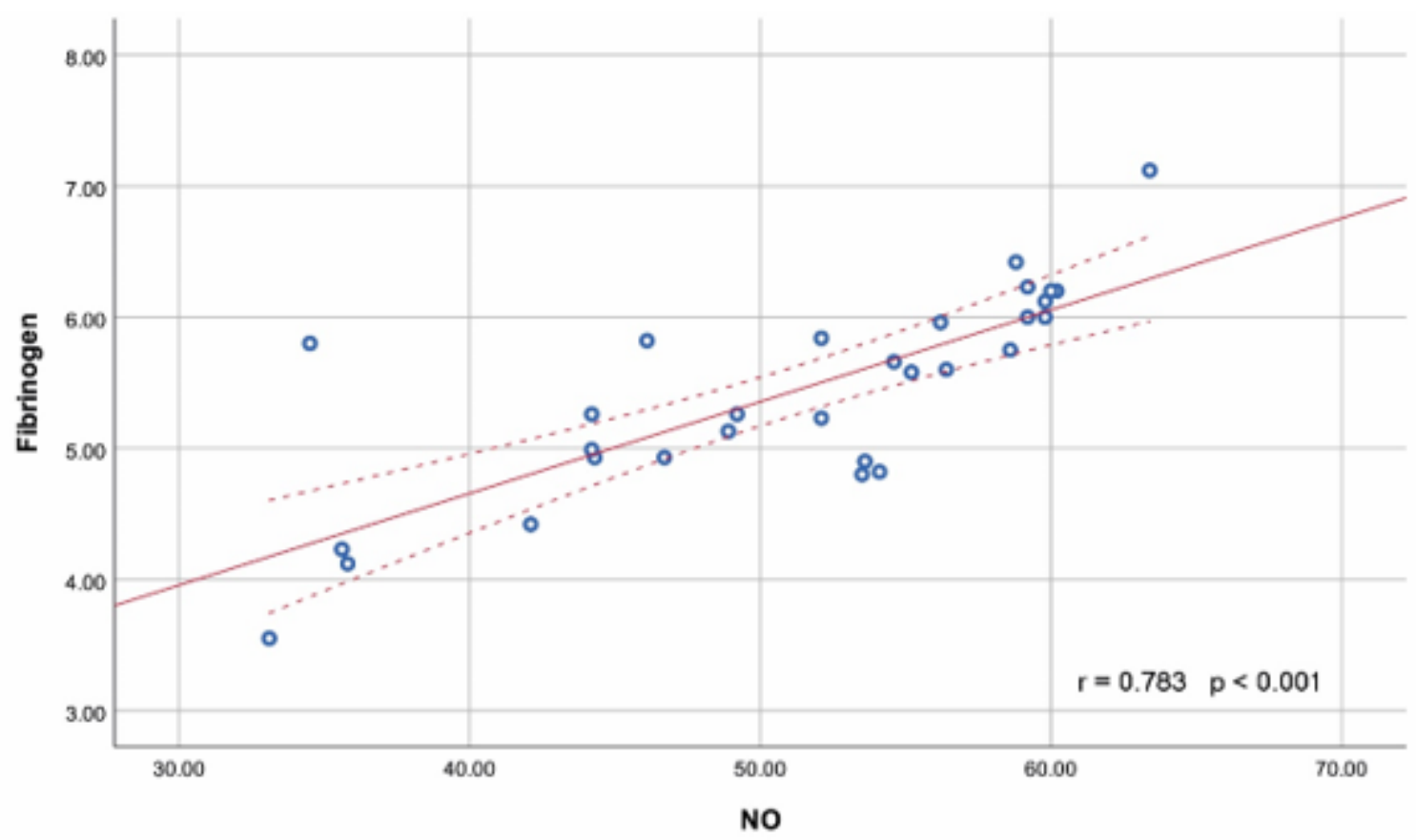

Figure 4

Relationship between Fibrinogen and NO for the patients group

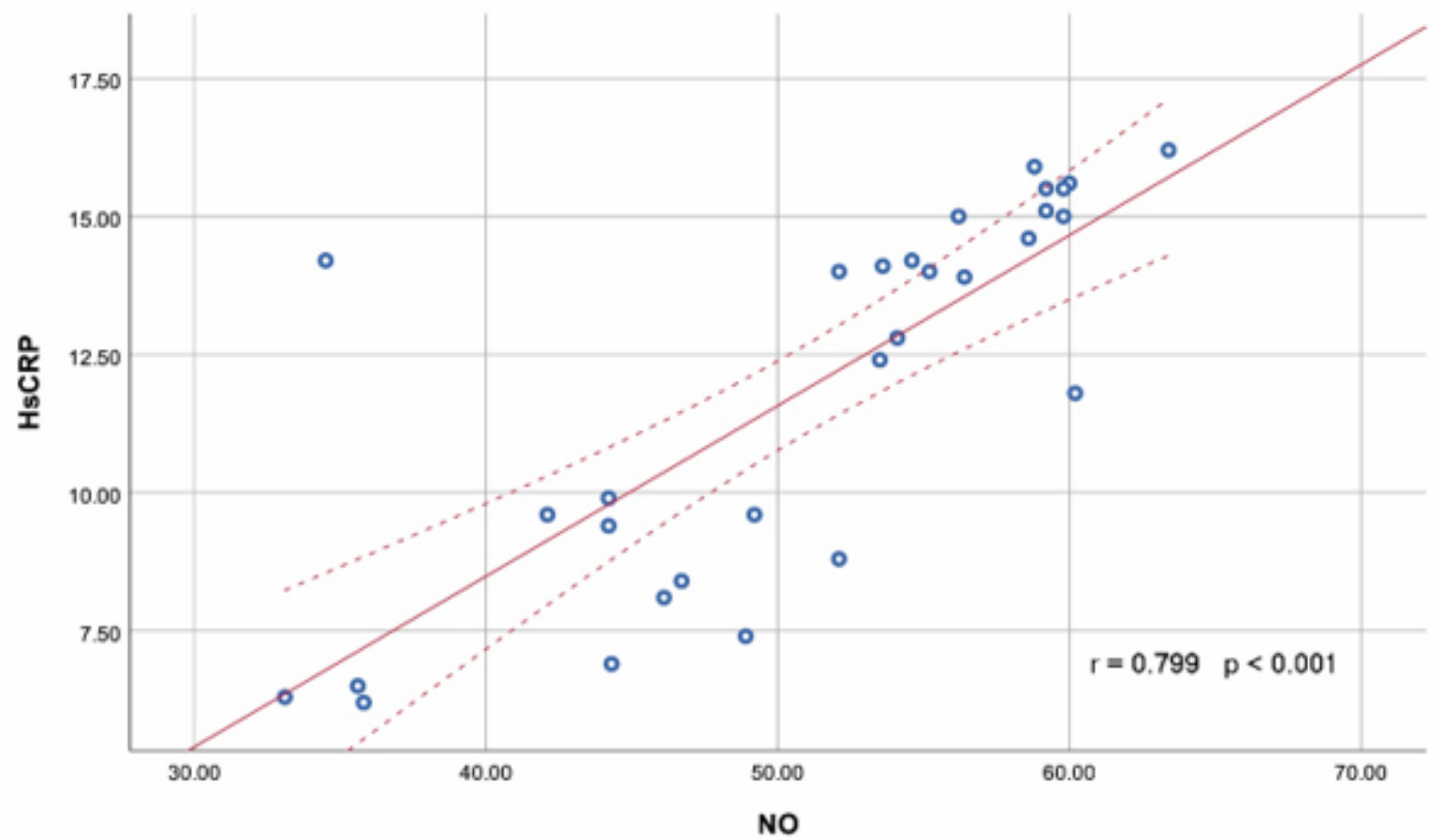

Figure 5

Relationship between HsCRP and NO for the patients group 


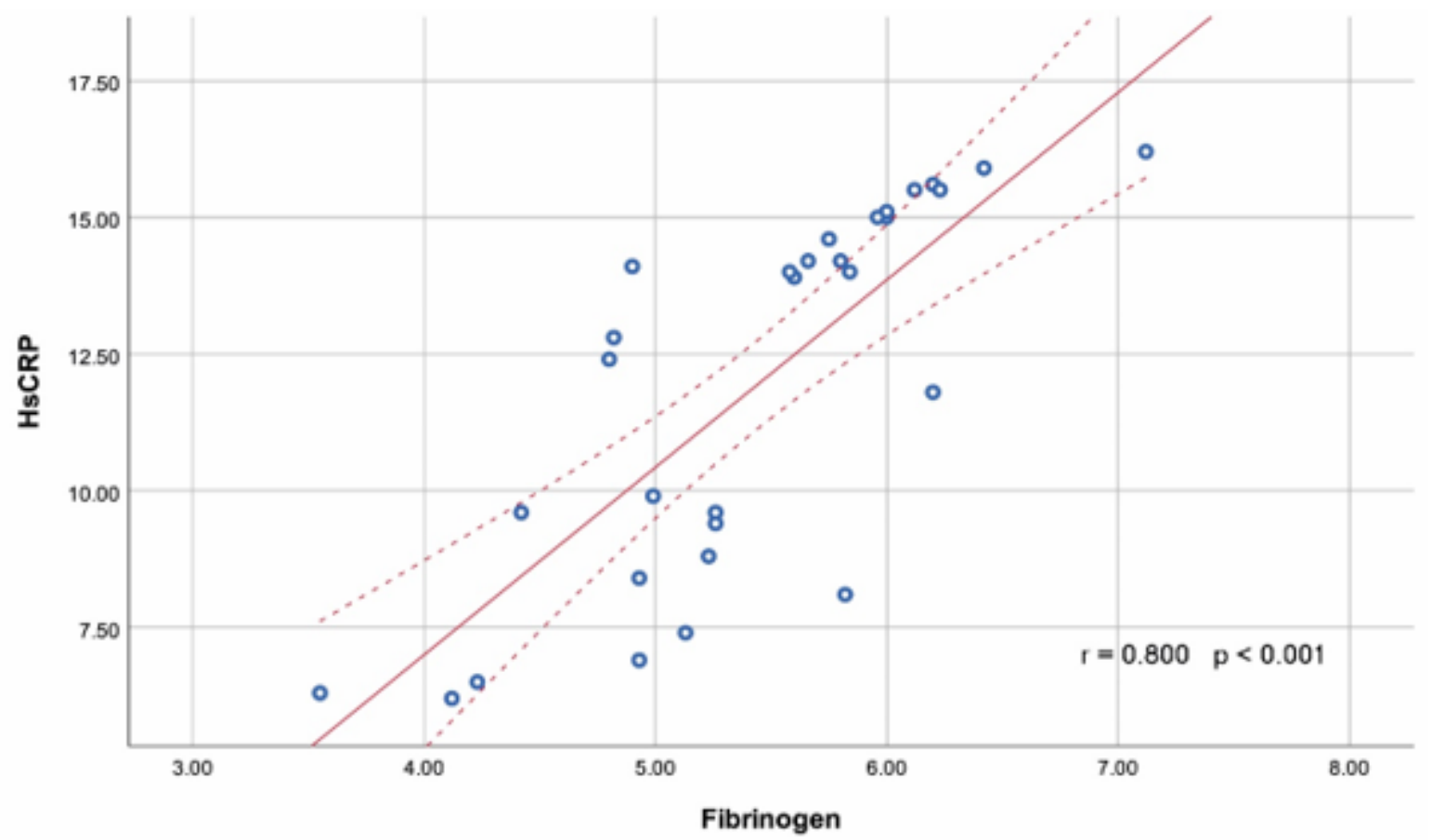

Figure 6

Relationship between HsCRP and Fibrinogen for the patients group 